\title{
The chemokinome superfamily in channel catfish: I. CXC subfamily and their involvement in disease defense and hypoxia responses
}

Qiang $\mathrm{Fu}^{\mathrm{a}}{ }^{\mathrm{b}}$, QifanZeng ${ }^{\mathrm{b}}$, Yun $\mathrm{Li}^{\mathrm{b}}$, YujiaYang ${ }^{\mathrm{b}}$, Chao $\mathrm{Li}^{\mathrm{c}}$, ShikaiLiu ${ }^{\mathrm{b}}$,Tao Zhou ${ }^{\mathrm{b}}$, Ning $\mathrm{Li}^{\mathrm{b}}$, Jun $\mathrm{Yao}^{\mathrm{b}}$, Chen Jiang ${ }^{\mathrm{b}}$,Daoji Li ${ }^{\mathrm{a}}$, Zhanjiang Liu ${ }^{\mathrm{b}, *}$

${ }^{a}$ State Key Laboratory of Estuarine and Coastal Research, East China Normal University, Shanghai 200062, China

${ }^{b}$ The Fish Molecular Genetics and Biotechnology Laboratory, Aquatic Genomics Unit, School of Fisheries, Aquaculture and Aquatic Sciences, Auburn University, Auburn, AL 36849, USA

${ }^{c}$ Marine Science and Engineering College, Qingdao Agricultural University, Qingdao 266109, China

*Corresponding author: Tel.: +1 334844 4054; fax: +1 334844 9208. E-mail address: liuzhan@auburn.edu 


\section{ABSTRACT}

Chemokines are a superfamily of structurally related chemotactic cytokines exerting significant roles in regulating cell migration and activation. They are defined by the presence of four conserved cysteine residues and are divided into four subfamilies depending on the arrangement of the first two conserved cysteines residues: CXC, CC, C and CX3C. In this study, a complete set of 17 CXC chemokine ligand (CXCL) genes was systematically identified and characterized from channel catfish genome through data mining of existing genomic resources. Phylogenetic analysis allowed annotation of the 17 CXC chemokines. Extensive comparative genomic analyses supported their annotations and orthologies, revealing the existence of fishspecific CXC chemokines and the expansion of CXC chemokines in the teleost genomes. The analysis of gene expression after bacterial infection indicated the CXC chemokines were expressed in a gene-specific manner. CXCL11.3 and CXCL20.3 were expressed significantly higher in resistant fish than in susceptible fish after ESC infection, while CXCL20.3 were expressed significantly higher in resistant fish than in susceptible fish after columnaris infection. The expression of those CXC chemokines, therefore can be a useful indicator of disease resistance. A similar pattern of expression was observed between resistant and susceptible fish with biotic and abiotic stresses, ESC, columnaris and hypoxia, suggesting that high levels of expression of the majority of CXC chemokines, with exception of CXC11 and CXC20, are detrimental to the host.

Key words: chemokine, fish, genome, innate immunity, disease resistance 


\section{Introduction}

Chemokines are a superfamily of chemotactic cytokines playing significant roles in regulating cell migration and activation under inflammatory conditions [1-3]. They are key immune regulators, acting as a bridge between innate and adaptive immunity[4].Specifically, chemokines promote leukocyte mobilization and regulate the immune responses and differentiation of the recruited cells[4, 5]. In addition to their roles in immunity, chemokines also participate in angiogenesis[6, 7], neurological development [8, 9], organogenesis and germ cell migration [10, 11], andhypoxia responses $[12,13]$. Chemokines are structurally related small peptides, typically 8-15 kDa, with majority of them containing four conserved cysteine residues $[3,14]$. Based on the arrangement of the first two of the cysteine residues, chemokines are divided into four subfamilies, CXC, CC, C and CX3C [15]. The CXC subfamily is one of the largest subfamilies.

Initially identified as effective mediators of neutrophil chemotaxis [16, 17], CXC chemokines are also known to function in chemotaxis of monocytes and lymphocytes [18, 19], acting by binding to G-protein-coupled cell surface receptors that can activate an array of signaling pathways[20, 21]. In mammals, the CXC subfamily consists of 17 members, but each species has slightly variable numbers of genes, with 16 members for human (lacking CXCL15), 15 for mouse (lacking CXCL6 and CXCL8) and a smaller number identified from other mammalian species [22]. CXC chemokines are further classified into two subgroups, $\mathrm{ELR}^{+}$and ELR', based on the presence or absence of a tri-amino acid motif (Glu-Leu-Arg or E-L-R) 
preceding the first conserved cysteine at the N-terminus [23-25]. In mammals, the $\mathrm{ELR}^{+}$ subgroup includes CXCL1, CXCL2, CXCL3, CXCL5, CXCL6, CXCL7, CXCL8 and CXCL15. These chemokines play major roles in promoting the adherence of neutrophils to endothelial cells and subsequent migration along a gradient of chemokines associated with matrix proteins and cell surfaces towards inflammatory sites [26]. In addition, the $\mathrm{ELR}^{+}$group exhibits angiogenic properties [19]. The ELR ${ }^{-}$chemokine group includes CXCL4, CXCL9, CXCL10, CXCL11, CXCL12, CXCL13, CXCL14 and CXCL16. They have functions to attract lymphocytes and monocytes, while with little or no ability for neutrophils [27, 28]. In contrast to ELR $^{+}$groups,most ELR ${ }^{-}$CXC chemokines are angiostatic and have anti-angiogentic characteristics [27].In teleost fish, the ELR motif is sometimes replaced by a defective DLR motif (Asp-Leu-Arg). Initially, this conservative change from E to D was assumed not to affect function[29]. However, the DLR motif has been demonstrated unnecessary for the attraction of neutrophils by fish CXC chemokines [30].

To date, six different CXC clades, includingCXCa, CXCb, CXCc, CXCd, CXCL12 and CXCL14 have been identified from teleost fish [31, 32].However, not all fish contained the six clades of CXC chemokine genes. Moreover, several fish-specific members were observed in CXC chemokines subfamily such as CXCa and CXCb in carp (Cyprinuscarpio)[31], and CXCd in rainbow trout (Oncorhynchus mykiss) [33]. In zebrafish, over 100 chemokine genes were initially reported [1], but the latest annotation included fewer number of chemokine genes, with 23 CXC chemokine genes (http://zfin.org/).

Channel catfish (Ictalurus punctatus)is a primary aquaculture species in the United States (http://www.fao.org/fishery/culturedspecies/Ictalurus_punctatus/en), but its sustainable production is threatened by severe disease outbreaks. In particular, the enteric septicemia of 
catfish (ESC)caused by Edwardsiellaictaluri, columnaris disease caused byFlavobacterium columnare, andthe emerging Aeromonas disease caused by Aeromonashydrophila, all bacterial diseases, cause major economic losses to the catfish industry [34, 35].The disease incidents were increased with exposures to environmental stresses, especially when exposed to hypoxia [36]. Understanding of molecular linkage between disease and hypoxia responsesshould help strategic thinking of solving these problems in genetic enhancing programs. With catfish, many innate immune genes have been characterized including pathogen recognition receptors [37-43], antimicrobial peptides [44-48], lysozymes [49], lectins [50-52], NOS genes [53], protease inhibitors [54, 55] and septins[56]. With chemokines, our previous studies [57-59] reported five members of CXC chemokines (CXCL2-like, CXCL8, CXCL10, CXCL12 and CXCL14). However, the entire chemokinome of CXC subfamily has not been conducted, and their involvement in disease and hypoxia responses has not been fully understood. The objective of this work was to determine all possible members of the CXC chemokine subfamily in channel catfish, and their expression after bacterial infections, and under hypoxia stress.

\section{Materials and methods}

\subsection{Gene identification and sequence analysis}

The CXC chemokine genes in channel catfish were identified by searching against the RNASeq database and the whole genome sequence database of catfish, using all available sequences of CXC chemokines from zebrafish (Danio rerio), fugu (Takifugurubripes), medaka (Oryziaslatipes), tongue sole (Cynoglossussemilaevis), frog (Xenopus laevis), chicken (Gallus gallus), mouse (Mus musculus), cow (Bos Taurus) and human (Homo sapiens) retrieved from the NCBI (http://www.ncbi.nlm.nih.gov/), Ensemble (http://www.ensembl.org) and ZFIN 
(http://zfin.org/). TBLASTN similarity searches were conducted firstly against channel catfish transcriptome database to identify the initial catfish CXC chemokine sequences using a cutoff Evalue of $1 \mathrm{e}^{-5}$. The transcriptome database was generated by RNA-Seq genome-guided assembly (unpublished), which is the most complete channel catfish transcriptome database building with about 4.8 billion raw reads. After that, duplicates in the initial sequence pool were eliminated by using Clustal Omega (http://www.ebi.ac.uk/Tools/msa/clustalo/) and each sequence was confirmed to be the unique gene according to their position information on the genome. Then, ORF (opening reading frames) finder (http://www.ncbi.nlm.nih.gov/gorf/gorf.html) was used to predict coding sequences, which were further validated by BLASTP against NCBI nonredundant (nr) protein database. In order to verify copy number and the sequence accuracy of CXC chemokine genes in channel catfish, BLASTN was performed against channel catfish whole genome database [60], using the initial pool of CXC chemokine mRNA sequences as queries, with a cutoff E-value of $1 \mathrm{e}^{-10}$. Fgenesh program of Molquest software (Softberry Int.) was used to predict the genes from retrieved genomic scaffold sequences [61]. The simple modular architecture research tool (SMART http://smart.embl-heidelberg.de) was used to identify the characteristic functional domains and further endorsed by conserved domain predicted through BLASTP. The catfish CXC chemokine amino acid sequences acquired above were used in the following phylogenetic analysis to determine gene identities.

\subsection{Phylogenetic analysis}

Phylogenetic analysis was conducted using the amino acid sequences of CXC chemokine from various organisms along evolutionary spectrum including human, mouse, chicken, frog and several fish species with inclusion of channel catfish, zebrafish, tongue sole, fugu and medaka. 
Alignment of multiple amino acid sequences were performed using MUSCLE (multiple sequence comparison by log-expectation) with default parameters [62]. The unrooted phylogenetic tree of CXC chemokines were constructed using MEGA 6 [63] with the maximum likelihood method. Based on the alignment results, JTT (Jones-Taylor-Thornton) + I (invariant sites) + G (gamma distribution for modeling rate heterogeneity) model was selected [64]. The bootstrapping with 1000 replications was performed to test the phylogenetic tree and gaps were removed by complete deletion. Bootstrap values less than 50 are not shown.

\subsection{Synteny analysis}

Syntenic analysis was conducted to better support the orthologies for the channel catfish CXC chemokine genes, basing on the comparison the neighbouring genes of CXC chemokines in channel catfish with zebrafish. Briefly, BLASTN was conducted using the catfish CXC chemokine coding sequences as queries against the catfish genome sequence database [60], with a cutoff E-value of $1 \mathrm{e}^{-10}$. The flanking genes of catfish CXC chemokines were predicted from the catfish genomic scaffolds using Fgenesh program Molquest software (Softberry Int.)[61] and validated by running BLASTP against NCBI non-redundant database. The genomic pattern of CXC chemokine genes and their neighboring genes in zebrafish were obtained from NCBI, Ensembl and Genomicus[65] database. For the nomenclatures of channel catfish CXC chemokine genes, since no clear orthology to mammalian chemokines could be established for most fish chemokines [1], we named them after zebrafish whenever possible, based on orthologues which determined by phylogenetic and syntenic analysis.

\subsection{Schematic genomic organization analysis}


Schematic genome structure of catfish CXC chemokine genes was analyzed in order to visually and systematically clarifying the distribution of CXC chemokine genes in catfish genome. The schematic genomic organization of catfish CXC chemokine genes illustrated the detailed information of catfish CXC chemokine genes, with inclusion of their genome positions, transcriptional orientation and numbers of coding exons. Such information was collected and decided from the identifications, annotations of catfish CXC chemokines.

\subsection{Expression analysis following E.ictaluri and F.columnare infections}

Meta-analysis of RNA-Seq data was conducted to determine the expression profiles of CXC chemokines in response to bacterial infections (E.ictaluri and F.columnare). The bacterial challenges were conducted as previously described [66-69] and all experiments were approved by the Institutional Animal Care and Use Committee (IACUC) at Auburn University.On the one hand, the expression of catfish CXC chemokines with time variation after ESC and columnaris infection were determined. Briefly, marion channel catfish (mean weight $35 \mathrm{~g}$ ) were maintained in $30 \mathrm{~L}$ tanks and acclimatized for 1 week at a temperature of $28{ }^{\circ} \mathrm{Cprior}$ to experiment. Bacterial was cultured from a single colony, re-isolated from a symptomatic fish and biochemically confirmed before being inoculated in the shaker incubator overnight. The concentration of bacteria was determined using colony forming unit (CFU) per $\mathrm{mL}$ by plating $10 \mu \mathrm{L}$ of 10 -fold serial dilutions onto plates. For ESC infection, fish were challenged in $30 \mathrm{~L}$ aquaria with three control and three treatment groups. Aquaria were randomly divided into three sampling timepoints: $3 \mathrm{~h}, 24 \mathrm{~h}$, and $72 \mathrm{~h}$ post-infection for both control and treatment groups. During challenge, E.ictaluri(MS-S97-773) with a concentration of $4 \times 10^{8} \mathrm{CFU} / \mathrm{mL}$ was added into the treatment aquaria for $2 \mathrm{~h}$ with the water flow turned off. Control fish were exposed to the same routines as 
treatment fish, but were immersed in sterilized media alone. At each time-point, 30 fish were collected from the control and treatment aquaria and anesthetized with MS-222 (300 mg/L). The entire intestinal tracts intestine from 10 fish (3 replicates of 10 fish each) were pooled together, flash frozen in liquid nitrogen and store at $-80^{\circ} \mathrm{C}$ until RNA extraction. Similarly, for columnaris challenge, fish were randomly divided into six $30 \mathrm{~L}$ aquaria of which three aquaria were used as control ( $4 \mathrm{~h}, 24 \mathrm{~h}$ and $48 \mathrm{~h}$ ) and the other three were used as challenge groups. F.columnare(BGFS-27; genomovar II ) with a concentration of $3 \times 10^{6} \mathrm{CFU} / \mathrm{mL}$ were added into the treatment aquaria for $2 \mathrm{~h}$. Gills of 18 fish were collected and randomly divided into three replicate pools (6 fish each) at each sampling time-point. Samples were flash-frozen in liquid nitrogen and stored at $-80{ }^{\circ} \mathrm{C}$ until RNA extraction.

On the other hand, the expression patterns of catfish CXC chemokines in susceptible and resistant fish to ESC and columnare were also determined. For the ESC challenge, catfish (mean weight 35 g) were challenged in $500 \mathrm{~L}$ (400 L water) aquaria with control group containing 400 fish and treatment group containing 1200 fish. The MS-S97-773 isolate of E.ictaluribacteria was obtained from a natural outbreak and utilized in the experimental challenge. All the experimental procedures including bacterial isolation, cultivation and infection were same with ESC challenge described above. During 3-5 days after challenge, all dying fish with classical ESC clinic signs were collected as susceptible fish. After two weeks of the challenge, all survival fish were collected as resistant fish and the fish in control group were also collected at that time. 72 fish (24 fish/group each for resistant, susceptible and control) were collected and anesthetized with MS-222 (300 mg/L). Equal amounts of liver tissue from 8 fish (3 replicates of 8 fish each) were pooled together, flash frozen in liquid nitrogen and store at $-80{ }^{\circ} \mathrm{C}$ until RNA extraction. For the columnaris challenge, two families of channel catfish ( mean weigh $14 \mathrm{~g}$ ) utilized in this study 
were previously revealed to have differing susceptibilities to columnaris disease [70, 71]. There were four tanks for each family, three of which were challenged with F.columnareand remaining tank for each family served as a negative (unchallenged) control. The fish were euthanized with MS-222 (300 mg/L) before tissues were collected. Gill tissues from 4 fish per replicate tank (3 replicates tanks/ family) were collected at $8 \mathrm{~h}$ after challenge. Equal amounts of tissues were collected from each fish within the three pools (3 pools of 4 fish each), flash frozen in liquid nitrogen and store at $-80{ }^{\circ} \mathrm{C}$ until RNA extraction.

Illumina-based RNA-Seq reads were retrieved from our four previous RNA-Seq datasets described above: intestine samples from catfish challenged with ESC (3h, 24h and $72 \mathrm{~h}$ post infection) (SRA accession number SRP009069)[66] and gill samples from catfish challenged with columnare (4h, 24h and 48h post infection) (SRA accession number SRP012586)[67] were used to determine the expression signatures of CXC chemokine genes with time variation, meanwhile, liver samples from catfish challenged with ESC (the comparison between resistant and susceptible groups) (SRA accession number SRP028159)[68] and gill samples from catfish challenged with columnare (the comparison between resistant and susceptible at 8 h)(SRA accession number SRP017689)[69] were used to compare the expression differences of CXC chemokine genes between susceptible and resistant catfish groups. The trimmed high quality RNA-Seq reads were first mapped to reference containing the whole 26,661 unique catfish cDNA transcripts together with all cDNA sequences of channel catfish CXC chemokine genes identified in this study. Mapping parameters were set as $95 \%$ or greater sequence identity with a maximum of two mismatches. The number of total mapped reads for each chemokine genes was determined and RPKM was calculated. The expression fold change of each chemokine gene was calculated based on normalized RPKM using proportions-based Kal's test. Chemokine genes 
with absolute fold change $\geq 2$, total reads number $>5$ and p-value $<0.05$ were regarded as differentially expressed genes (DEGs).

\subsection{Expression analysis following hypoxia stress}

For hypoxia challenge, 350 catfish (average body mass $21.73 \mathrm{~g}$ ) were acclimated in an aquarium $[90 \times 60 \times 30 \mathrm{~cm}(\mathrm{~L} \times \mathrm{W} \times \mathrm{H})]$ for one week with flow-through water. After acclimation, 50 fish were moved to another tank as control group, the remaining fish were exposed to hypoxia stress. Dissolved oxygen levels in the challenge group were reduced from $8.5 \mathrm{mg} / \mathrm{L}$ to $1.00 \mathrm{mg} / \mathrm{L}$ after bubbling nitrogen gas into the aquarium for $1.5 \mathrm{~h}$. The oxygen level was measured every hour to ensure the oxygen concentration was properly maintained. Starting at $1.5 \mathrm{~h}$ when first fish start to lose balance, samples were collected continuously until 45 fish were collected. At $5 \mathrm{~h}$ after low oxygen challenge, 45 tolerant fish were randomly collected. 15 fish were euthanized with MS-222 (300 mg/L) and collected for hypoxia intolerant, tolerant and control group. Gill samples were collected and pooled for RNA analysis. The similar meta-analysis was conducted

to determine the expression signatures of CXC chemokine between hypoxia-tolerant and hypoxia-intolerant fish using our previous Illumina-based RNA-Seq datasets (SRA no.SRP039612)[72]. The differential expression analyses were conducted the same as described above in bacterial infectious tissues (see 2.5).

\section{Results}

3.1 Identification of CXC chemokine genes in channel catfish

A total of 17 CXC chemokine genes were identified in the channel catfish genome including CXCL8a, CXCL8b.1, CXCL8b.2, CXCL11.1, CXCL11.2, CXCL11.3, CXCL12a, CXCL12b, 
CXCL13, CXCL14, CXCL18a.1, CXCL18a.2, CXCL18b, CXCL19, CXCL20.1, CXCL20.2 and

CXCL20.3. Their sequences were deposited to GenBank. The characteristics of the transcripts of the 17 CXC chemokines, including the transcript sizes, coding sequences, gene organizations and their chromosomal locations, and their accession numbers are shown in Table 1.The transcripts of the catfish CXC chemokines vary between 506-3,040 bp encoding proteins of 90 to 131 amino acids (Table 1). Most catfish CXC genes have 4 exons with exception of three genes: CXCL20.1 has 3 exons; and CXCL11.3 and CXC18a.2 have 5 exons each. As shown in Supplementary figure S1, all members of the catfish CXC chemokines possessed the conserved CXC domain.

\subsection{Phylogenetic and syntenic analysis of channel catfish CXC chemokine genes}

Phylogenetic analysis was conducted to annotate the channel catfish CXC chemokine genes. Overall, phylogenetic analysis supported the annotation of catfish CXC chemokines. Most of the channel catfish CXC chemokines were clustered into clades with their respective counterparts in zebrafish with strong bootstrap support. Of the 17 catfish CXC chemokines, a number of them are highly related duplicates, which included three genes for CXCL8: 8a, 8b.1 and 8b.2; three genes for CXCL11: 11.1, 11.2 and 11.3; two genes for CXCL12: 12a and 12b; three genes for CXCL18: 18a.1, 18a.2 and 18b; and three genes for CXCL20: 20.1, 20.2 and 20.3 (Fig. 1)

Though phylogenetic relationships provided strong support for the identities of most catfish CXC chemokines, syntenic analyses were necessary to provide additional support for the annotation of CXCL8, CXCL11, CXCL12, CXCL18, CXCL20 and their duplicates. As shown in Figure 2, the three CXCL8 genes were derived from the initial whole genome duplication, followed by a tandem duplication (Fig. 2A). The orthology of CXCL11 and CXCL20 is 
somewhat complex. In the genomic neighborhood, it appeared that the earliest module included one copy each of CXCL20 and CXCL11. Then, tandem gene duplication of CXCL11 in zebrafish led to four copies of CXCL11; in contrast, in catfish the whole segment containing both CXCL20 and CXCL11 were duplicated in a tandem fashion, leading to three copies each of CXCL20 and CXCL11 (Figure 2B). CXCL12a and CXCL18a.1 are located together, and the conserved syntenic region in catfish was found to contain these genes as well, except that CXCL18a gene was tandemly duplicated, forming CXCL18a.1 and CXCL18a.2. The syntenic blocks containing CXCL12b and CXCL18b were well conserved between zebrafish and catfish, with some local differences in gene orientations. Overall, the syntenic analysis validated the annotation of CXC chemokine genes.

\subsection{Comparative analysis of copy numbers of CXC chemokine genes}

The copy numbers of CXC chemokine genes are listed in Table 2. Zebrafish has the largest number of total CXC chemokine genes (23 genes) followed by catfish (17 genes), human (16 genes), mouse (15 genes), cow (14 genes), and a number of fish species. However, the diversity of mammalian CXC chemokines were much larger than those in teleost fish species. For instance, human has 16 CXC chemokine genes, with each of them a single copy. In contrast, the 17 copies of the catfish CXC chemokine genes were derived from both chromosomal duplication and tandem duplication, with original only 8 genes. Similar situation is true with zebrafish and other fish species. However, four CXC chemokines were found only in teleost fish, presumably to be teleost-specific. They are CXCL18, CXCL19, CXCL20, and CXCL32. Among all CXC chemokines, only three, CXCL12, CXCL13, and CXCL14, were shared by various organisms ranging from teleost fish to mammals (Table 2). 
As shown in Figure 3, the 17 channel catfish CXC chemokine genes are distributed on seven different chromosomes in clusters: chromosome 22 contained the largest number of CXC chemokines with seven genes; followed with chromosomes 3 and 7, with each of them containing three CXC chemokine genes; Chromosome 8, 26, 27 and 29 each has one chemokine gene (Fig. 3).

\subsection{Expression of CXC chemokine genes following bacterial infection}

The expression of 17 catfish CXC chemokines was determined after bacterial infections with two pathogens, E. ictaluri and F. columnare using RNA-Seq datasets. Expression after ESC bacterial infection was determined using RNA-Seq dataset of intestine. After ESC infection, expression for the most CXC chemokine genes was not significantly affected. However, four chemokine genes, CXCL12a, CXCL12b, CXCL18b and CXCL20.3 were significantly up-regulated except CXCL20.3 at 24h after infection when it was down-regulated (Fig. 4).

Expression of CXC chemokine genes after columnaris bacterial infection was shown in Figure 5. Four of the 17 CXC chemokine genes, were differentially expressed, of which CXCL18a.2, CXCL18b and CXCL20.3 were induced at 24 hour post-infection, while CXCL11.3 was suppressed at 24 hour and 48 hour post-infection (Fig. 5).

\subsection{Comparison of CXC chemokine expression in resistant and susceptible fish}

The comparison of CXC chemokine expression between resistant fish and susceptible fish in liver was determined after ESC infection. As shown in Figure 6, six CXC chemokine genes (CXCL8a, CXCL8b.2, CXCL12a, CXCL14, CXCL18a.2 and CXCL18b) were expressed 
significantly higher in susceptible fish than in resistant fish while two CXCL chemokines (CXCL11.3 and CXCL20.3) were expressed at mildly higher levels in resistant fish after ESC infection (Fig. 6).

The similar expression patterns of CXC chemokine genes between resistant fish and susceptible fish after columnaris infection were observed. Higher expression in resistant fish was only observed one CXC chemokine, CXCL20.2 (Fig. 7), while higher expression in susceptible fish was observed with four CXC chemokines, CXCL8b.1, CXCL8b.2, CXCL11.2 and CXCL20.1 (Fig. 7). In addition, expression levels in susceptible fish was much higher after infection than in resistance fish (Fig. 7).

\subsection{Expression profile of CXC chemokine genes following hypoxia stress}

To get insights to the potential involvement of CXC chemokine in hypoxia responses, the expression profile of catfish CXC chemokines under hypoxia conditions was determined. The comparison between tolerant group and intolerant group revealed that there were eight CXC chemokine genes showing differentially expressed patterns between the hypoxia-tolerant fish and hypoxia-intolerant fish. Among them, seven genes (CXCL8a, CXCL11.1, CXCL11.2, CXCL11.3, CXCL13, CXCL18a.2, and CXCL20.1) were expressed significantly higher in intolerant fish than in tolerant fish while only one gene (CXCL12b) was expressed higher in tolerant fish than in intolerant fish (Fig. 8).

\section{Discussion}

Chemokines are a class of important chemotactic cytokines, serving as key regulators for cell migration and activation, especially under inflammatory conditions [1, 2]. As a major chemokine 
subfamily, the CXC chemokines play fundamental roles in development, homeostasis and immune responses through regulating neutrophil chemotaxis [16, 17] and functioning in chemotaxis of monocytes and lymphocytes $[18,19]$. In spite of their significance, systematic analysis of CXC chemokines is scarce in fish species [1]. Only five catfish CXC chemokines were previously identified [57-59], however, four of them were not annotated properly due to the lack of genome sequence which became recently available for catfish [60] and lack of information from other fish species at that time. In the present study, we identified a complete repertoire of 17 CXC chemokine genes in channel catfish, conducted structural, phylogenetic, syntenic analysis, and determined their expression patterns after bacterial infections and after hypoxia challenges. These results should be valuable for comparative immunological studies and provide insights into their roles in stress response.

The annotations of catfishCXC chemokine gene family were fairly explicit based on the phylogenetic and syntenic analyses. First of all, phylogenetic analysis provided straightforward perceptions to their identification and the evolutional relationship. As shown in Fig. 1, all catfish CXC chemokines were clustered with their respective counterparts from other teleosts, hence the annotation of the catfish CXC chemokines genes were relatively forthright. In addition, with CXCL8, 11, 12, 18 and 20, syntenic analysis provided further evidence for their orthologies and evolutionary origins (Fig. 2), supporting their annotations. Mammal CXC chemokines has been divided into two subgroups with inclusion of ELR+subgroup and ELR- subgroup, based on the presence or absence of the ELR motif. However, as shown in Supplementary Fig. S1, none of the catfish CXC chemokines, including CXCL8, contains ELR motif. In fish, the ELR motif is usually replaced by a defective DLR motif [29]. However, it has been demonstrated that this DLR motif is not essential for fish CXC chemokines [30]. 
Analysis of the copy numbers of CXC chemokines in teleost fish and tetrapods provided insights to the evolution of CXC chemokines. Firstly, the present study endorses and extends previous research about expansion of CXC chemokines in teleost fish $[1,4,14]$. Seventeen CXC chemokines were identified in catfish in the present study (Table 2), compared to seven found in amphibians (Frog), four in reptiles and five in birds [14]. There are two major factors leading to the expansion of CXC chemokines in teleost fish, the duplications and the existence of fishspecific chemokines. On the one hand, duplications for some genes (CXCL8, CXCL11, CXCL12, CXCL18, CXCL20 and CXCL32) were only found in teleosts, through both whole genome duplication and lineage-specific tandem gene duplications [73, 74]. Syntenic analysis confirmed this and also supported the intrachromosomal segmental duplication of some CXC chemokines in catfish [56]. For example, the catfish CXCL8b.1 and CXCL8b.2 were tandemly located on the chromosome 7, and CXCL18a.1 and CXCL18a.2 were also tandemly located on chromosome 3, both clearly indicated the segmental duplications (Fig. 2). On the other hand, the existence of fish-specific CXC chemokines were also observed in the present study, which have been reported in several fish species such as zebrafish and rainbow trout [1, 14, 33]. Moreover, CXCL12 and CXCL14 were found in all analyzed species, which supported the conclusion that CXCL12 and CXCL14 are the two most evolutionarily conserved chemokines [22, 75]. In addition, with minor exceptions, a set of 12 CXC chemokines including CXCL1, CXCL2, CXCL3, CXCL4, CXCL5, CXCL6, CXCL7, CXCL9, CXCL10, CXCL15, CXCL16 and CXCL17were only harbored by mammalian species and were lacking in other species (Table 2). Those mammal-specific CXC chemokines are believed to have derived by gene duplication after the divergence of the bird and mammalian ancestral lineages [14, 25].

It has been comprehensively studied and well accepted that CXC chemokines not only exert 
vital roles in development and homeostasis but also in inflammatory responses in humans [2, 75, 76]. However, in fish species, the involvements of CXC chemokines in immune responses were only sporadically reported. Therefore, we examined the expression profiles of $17 \mathrm{CXC}$ chemokines following the infection of E. ictaluri and F. columnarein channel catfish. In general, CXC genes were induced after bacterial infections, though not all CXC chemokines, and with the exception of CXC11.3 that was down-regulated after infection (Fig. 5). In addition, fish-specific CXC chemokines may play important roles in fish immune responses, as expression of several CXC chemokines, e.g., CXCL18 and CXCL 20, were induced after two bacterial infections(Fig. 4 and Fig. 5). Although the functions of fish-specific CXC chemokines in fish immunity are currently poorly understood [14], the expression patterns should be useful for future studies concerning functional analysis of CXC chemokines.

Comparison of CXC chemokine expression between resistant and susceptible fish is the most interesting. In most cases, expression of most CXC chemokines was more significantly induced in the susceptible fish than in resistant fish, suggesting that expression of the majority of CXC chemokines was correlated with disease susceptibility (Fig. 6 and Fig. 7). Exceptions, however, do exist. With CXCL11.3 and CXCL20.3, expression was greater in resistant fish than in susceptible fish after ESC infection (Fig. 6), suggesting that high expression of these CXC chemokines might be beneficial to the host, enhancing its immunity against the pathogen without damaging the host. Interestingly, one copy of CXCL20 (CXCL20.2) are also expressed at higher levels in resistant fish than susceptible fish aftercolumnarisinfection (Fig. 7). The mechanisms of the potential beneficial effect of CXCL20 chemokines are unknown at the present. They are teleost-specific, and their roles have not been well studied. However, CXCL11 was reported to have potent antitumor activity through attraction of cytotoxic $\mathrm{T}$ lymphocytes and inhibition of 
angiogenesis [22, 77]. While we do not know the exact mechanism of how CXCL11 exert its beneficial effect for the host in teleost fish, a similar mechanism could provide the host with enhanced immune activities through attraction of cytotoxic T lymphocytes, as it does in humans [77].

A similar pattern was observed between the hypoxia-tolerant and intolerant groups, with the majority of CXC chemokines being expressed at higher levels in hypoxia-intolerant fish than in tolerant fish. The only exception is CXCL12b that is significantly induced in hypoxia-tolerant fish (Fig. 8). This suggest that high expression of CXCL12b is correlated with increased tolerance against low oxygen [78]. On the contrary, the significantly induced expression of most CXC chemokine genes in intolerant fish may indicate that high levels of induced CXC chemokines are indicative of sensitivity of fish for stress tolerance. This parallels with the disease susceptibility. In other words, a set of chemokines were expressed significantly higher in susceptible fish and in intolerant fish than in resistant and tolerant fish. This correlation is very interesting because stresses including hypoxia stress tended to induce disease incidents [36]. There is apparently a common linkage between disease infection and low oxygen stresses, and CXC chemokines could be a common set of molecular signals amplifying the adverse effect of infections or stresses. Future studies are required to provide detailed molecular mechanisms of stress responses and their effect on disease susceptibility.

\section{Conclusion}

In this study, the entire CXC chemokinome, with a total of 17 CXC chemokine genes, was systematically identified and characterized in the channel catfish genome. Phylogenetic and syntenic analysis allowed annotations of these genes, and provided insights into the existence of 
fish-specific CXC chemokines and the expansion of CXC chemokines in the teleost genomes. The analysis of gene expression after bacterial infection indicated the CXC chemokines were expressed in a gene-specific manner. CXCL11.3 and CXCL20.3 were expressed significantly higher in resistant fish than in susceptible fish after ESC infection, while CXCL20.3 were expressed significantly higher in resistant fish than in susceptible fish after columnaris infection. The expression of those CXCL chemokines, therefore can be a useful indicator of disease resistance.A similar pattern was observed with hypoxia, suggesting a common linkage of the host response to biotic and abiotic stresses. These studies should set the foundation for future studies of stress physiology and host-pathogen interactions.

\section{Acknowledgements}

This project was supported by USDA National Institute of Food and Agriculture through a grant from Animal Disease Program (2015-67015-22975), and from Agriculture and Food Research Initiative Animal Genomics, Genetics and Breeding Program (2015-67015-22907), and partially supported by USDA Aquaculture ResearchProgram Competitive Grant (2014-7000722395). We are grateful to the availability of RNA-Seq datasets produced by our group and Dr. Eric Peatman's research group. Qiang Fu was supported by a scholarship from the China Scholarship Council (CSC). 


\section{References}

[1] H. Nomiyama, K. Hieshima, N. Osada, Y. Kato-Unoki, K. Otsuka-Ono, S. Takegawa, T. Izawa, A. Yoshizawa, Y. Kikuchi, S. Tanase, R. Miura, J. Kusuda, M. Nakao, O. Yoshie. Extensive expansion and diversification of the chemokine gene family in zebrafish: identification of a novel chemokine subfamily CX. BMC Genomics 9 (2008) 222. [2] A. Zlotnik, O. Yoshie. Chemokines: a new classification system and their role in immunity. Immunity 12 (2000) 121-127.

[3] E. Peatman, Z. Liu. Evolution of CC chemokines in teleost fish: a case study in gene duplication and implications for immune diversity. Immunogenetics 59 (2007) 613-623.

[4] A. Alejo, C. Tafalla. Chemokines in teleost fish species. Dev. Comp. Immunol. 35 (2011) 1215-1222.

[5] C. Esche, C. Stellato, L.A. Beck. Chemokines: key players in innate and adaptive immunity. J. Invest. Dermatol. 125 (2005) 615-628.

[6] D.A. Arenberg, P.J. Polverini, S.L. Kunkel, A. Shanafelt, J. Hesselgesser, R. Horuk, R.M. Strieter. The role of CXC chemokines in the regulation of angiogenesis in non-small cell lung cancer. J. Leukoc. Biol. 62 (1997) 554-562.

[7] M.P. Keane, D.A. Arenberg, B.B. Moore, C.L. Addison, R.M. Strieter. CXC chemokines and angiogenesis/angiostasis. Proc. Assoc. Am. Physicians. 110 (1998) 288-296.

[8] R.J. Gordon, A.L. McGregor, B. Connor. Chemokines direct neural progenitor cell migration following striatal cell loss. Mol. Cell. Neurosci. 41 (2009) 219-232.

[9] A. Belmadani, P.B. Tran, D. Ren, R.J. Miller. Chemokines regulate the migration of neural progenitors to sites of neuroinflammation. J. Neurosci. 26 (2006) 3182-3191.

[10] M. Doitsidou, M. Reichman-Fried, J. Stebler, M. Koprunner, J. Dorries, D. Meyer, C.V. Esguerra, T. Leung, E. Raz. Guidance of primordial germ cell migration by the chemokine SDF-1. Cell 111 (2002) 647-659.

[11] H. Knaut, C. Werz, R. Geisler, C. Nusslein-Volhard, C. Tubingen Screen. A zebrafish homologue of the chemokine receptor Cxcr4 is a germ-cell guidance receptor. Nature 421 (2003) 279-282.

[12] T. Schioppa, B. Uranchimeg, A. Saccani, S.K. Biswas, A. Doni, A. Rapisarda, S. Bernasconi, S. Saccani, M. Nebuloni, L. Vago, A. Mantovani, G. Melillo, A. Sica. Regulation of the chemokine receptor CXCR4 by hypoxia. J. Exp. Med. 198 (2003) 1391-1402.

[13] M.C. Bosco, M. Puppo, C. Santangelo, L. Anfosso, U. Pfeffer, P. Fardin, F. Battaglia, L. Varesio. Hypoxia modifies the transcriptome of primary human monocytes: modulation of novel immune-related genes and identification of CC-chemokine ligand 20 as a new hypoxia-inducible gene. J. Immunol. 177 (2006) 1941-1955.

[14] J. Chen, Q. Xu, T. Wang, B. Collet, Y. Corripio-Miyar, S. Bird, P. Xie, P. Nie, C.J. Secombes, J. Zou. Phylogenetic analysis of vertebrate CXC chemokines reveals novel lineage specific groups in teleost fish. Dev. Comp. Immunol. 41 (2013) 137-152.

[15] B. Bao, E. Peatman, X. Peng, P. Baoprasertkul, G. Wang, Z. Liu. Characterization of 23 CC chemokine genes and analysis of their expression in channel catfish (Ictalurus punctatus). Dev. Comp. Immunol. 30 (2006) 783-796.

[16] A. Walz, P. Peveri, H. Aschauer, M. Baggiolini. Purification and amino acid sequencing of NAF, a novel neutrophil-activating factor produced by monocytes. Biochem. Biophys. Res. Commun. 149 (1987) 755-761.

[17] T. Yoshimura, K. Matsushima, S. Tanaka, E.A. Robinson, E. Appella, J.J. Oppenheim, E.J. Leonard. Purification of a human monocyte-derived neutrophil chemotactic factor that has peptide sequence similarity to other host defense cytokines. Proc. Natl. Acad. Sci. 84 (1987) 9233-9237.

[18] A.E. Koch, P.J. Polverini, S.L. Kunkel, L.A. Harlow, L.A. DiPietro, V.M. Elner, S.G. Elner, R.M. Strieter. Interleukin-8 as a macrophage-derived mediator of angiogenesis. Science 258 (1992) 1798-1801.

[19] R.M. Strieter, P.J. Polverini, S.L. Kunkel, D.A. Arenberg, M.D. Burdick, J. Kasper, J. Dzuiba, J. Van Damme, A. Walz, D. Marriott, et al. The functional role of the ELR motif in CXC chemokine-mediated angiogenesis. J. Biol. Chem. 270 (1995) 27348-27357.

[20] A.D. Luster. Chemokines--chemotactic cytokines that mediate inflammation. N. Engl. J. Med. 338 (1998) 436445.

[21] M. Baggiolini. Chemokines and leukocyte traffic. Nature 392 (1998) 565-568.

[22] A. Zlotnik, O. Yoshie, H. Nomiyama. The chemokine and chemokine receptor superfamilies and their molecular evolution. Genome Biol. 7 (2006) 243.

[23] M.T. Pisabarro, B. Leung, M. Kwong, R. Corpuz, G.D. Frantz, N. Chiang, R. Vandlen, L.J. Diehl, N. Skelton, H.S. Kim, D. Eaton, K.N. Schmidt. Cutting edge: novel human dendritic cell- and monocyte-attracting chemokine-like 
protein identified by fold recognition methods. J. Immunol. 176 (2006) 2069-2073.

[24] M. Matloubian, A. David, S. Engel, J.E. Ryan, J.G. Cyster. A transmembrane CXC chemokine is a ligand for HIVcoreceptor Bonzo. Nat. Immunol. 1 (2000) 298-304.

[25] J. Wang, D.L. Adelson, A. Yilmaz, S.H. Sze, Y. Jin, J.J. Zhu. Genomic organization, annotation, and ligand-receptor inferences of chicken chemokines and chemokine receptor genes based on comparative genomics. BMC Genomics $6(2005) 45$.

[26] K.J. Laing, C.J. Secombes. Chemokines. Dev. Comp. Immunol. 28 (2004) 443-460.

[27] J.J. Oppenheim, O.Z. Howard, E. Goetzl, Chemotactic factors, neuropeptides, and other ligands for seven transmembrane receptors, Cytokine reference: a compendium of cytokines and other mediators of host defence, Academic Press London2000, pp. 985-1021.

[28] E.J. Fernandez, E. Lolis. Structure, function, and inhibition of chemokines. Annu. Rev. Pharmacol. Toxicol. 42 (2002) 469-499.

[29] C.A. Hebert, R.V. Vitangcol, J.B. Baker. Scanning mutagenesis of interleukin-8 identifies a cluster of residues required for receptor binding. J. Biol. Chem. 266 (1991) 18989-18994.

[30] Z. Cai, C. Gao, Y. Zhang, K. Xing. Functional characterization of the ELR motif in piscine ELR+CXC-like chemokine. Mar. Biotechnol. (NY) 11 (2009) 505-512.

[31] M.O. Huising, E. Stolte, G. Flik, H.F. Savelkoul, B.M. Verburg-van Kemenade. CXC chemokines and leukocyte chemotaxis in common carp (Cyprinus carpio L.). Dev. Comp. Immunol. 27 (2003) 875-888.

[32] M.O. Huising, T. van der Meulen, G. Flik, B.M. Verburg-van Kemenade. Three novel carp CXC chemokines are expressed early in ontogeny and at nonimmune sites. Eur. J. Biochem. 271 (2004) 4094-4106.

[33] G.D. Wiens, G.W. Glenney, S.E. Lapatra, T.J. Welch. Identification of novel rainbow trout (Onchorynchus mykiss) chemokines, CXCd1 and CXCd2: mRNA expression after Yersinia ruckeri vaccination and challenge. Immunogenetics 58 (2006) 308-323.

[34] B.A. Wagner, D.J. Wise, L.H. Khoo, J.S. Terhune. The epidemiology of bacterial diseases in food-size channel catfish. Journal of Aquatic Animal Health 14 (2002) 263-272.

[35] C.A. Shoemaker, O. Olivares-Fuster, C.R. Arias, P.H. Klesius. Flavobacterium columnare genomovar influences mortality in channel catfish (Ictalurus punctatus). Vet. Microbiol. 127 (2008) 353-359.

[36] X. Geng, J. Feng, S. Liu, Y. Wang, C. Arias, Z. Liu. Transcriptional regulation of hypoxia inducible factors alpha (HIF-alpha) and their inhibiting factor (FIH-1) of channel catfish (Ictalurus punctatus) under hypoxia. Comp. Biochem. Physiol. B Biochem. Mol. Biol. 169 (2014) 38-50.

[37] P. Baoprasertkul, E. Peatman, J. Abernathy, Z.J. Liu. Structural characterisation and expression analysis of tolllike receptor 2 gene from catfish. Fish Shellfish Immunol. 22 (2007) 418-426.

[38] P. Baoprasertkul, E. Peatman, B. Somridhivej, Z.J. Liu. Toll-like receptor 3 and TICAM genes in catfish: speciesspecific expression profiles following infection with Edwardsiella ictaluri. Immunogenetics 58 (2006) 817-830.

[39] P. Baoprasertkul, P. Xu, E. Peatman, H. Kucuktas, Z. Liu. Divergent toll-like receptors in catfish (Ictalurus punctatus): TLR5S, TLR20, TLR21. Fish Shellfish Immunol. 23 (2007) 1218-1230.

[40] K.V. Rajendran, J.R. Zhang, S.K. Liu, H.Y. Kucuktas, X.L. Wang, H. Liu, Z.X. Sha, J. Terhune, E. Peatman, Z.J. Liu. Pathogen recognition receptors in channel catfish: I. Identification, phylogeny and expression of NOD-like receptors. Dev. Comp. Immunol. 37 (2012) 77-86.

[41] K.V. Rajendran, J.R. Zhang, S.K. Liu, E. Peatman, H. Kucuktas, X.L. Wang, H. Liu, T. Wood, J. Terhune, Z.J. Liu. Pathogen recognition receptors in channel catfish: II. Identification, phylogeny and expression of retinoic acidinducible gene I (RIG-I)-like receptors (RLRs). Dev. Comp. Immunol. 37 (2012) 381-389.

[42] J.R. Zhang, S.K. Liu, K.V. Rajendran, L.Y. Sun, Y. Zhang, F.Y. Sun, H. Kucuktas, H. Liu, Z.J. Liu. Pathogen recognition receptors in channel catfish: III Phylogeny and expression analysis of Toll-like receptors. Dev. Comp. Immunol. 40 (2013) 185-194.

[43] L.Y. Sun, S.K. Liu, R.J. Wang, C. Li, J.R. Zhang, Z.J. Liu. Pathogen recognition receptors in channel catfish: IV. Identification, phylogeny and expression analysis of peptidoglycan recognition proteins. Dev. Comp. Immunol. 46 (2014) 291-299.

[44] B.L. Bao, E. Peatman, P. Li, C.B. He, Z.J. Liu. Catfish hepcidin gene is expressed in a wide range of tissues and exhibits tissue-specific upregulation after bacterial infection. Dev. Comp. Immunol. 29 (2005) 939-950.

[45] B.L. Bao, E. Peatman, P. Xu, P. Li, H. Zeng, C.B. He, Z.J. Liu. The catfish liver-expressed antimicrobial peptide 2 (LEAP-2) gene is expressed in a wide range of tissues and developmentally regulated. Mol. Immunol. 43 (2006) 367377. 
[46] Q. Wang, B.L. Bao, Y.P. Wang, E. Peatman, Z.J. Liu. Characterization of a NK-lysin antimicrobial peptide gene from channel catfish. Fish Shellfish Immunol. 20 (2006) 419-426.

[47] Q. Wang, Y.P. Wang, P. Xu, Z.J. Liu. NK-lysin of channel catfish: Gene triplication, sequence variation, and expression analysis. Mol. Immunol. 43 (2006) 1676-1686.

[48] P. Xu, B.L. Bao, Q. He, E. Peatman, C.B. He, Z.J. Liu. Characterization and expression analysis of bactericidal permeability-increasing protein (BPI) antimicrobial peptide gene from channel catfish Ictalurus punctatus. Dev. Comp. Immunol. 29 (2005) 865-878.

[49] R.J. Wang, J.B. Feng, C. Li, S.K. Liu, Y. Zhang, Z.J. Liu. Four lysozymes (one c-type and three g-type) in catfish are drastically but differentially induced after bacterial infection. Fish Shellfish Immunol. 35 (2013) 136-145.

[50] T. Takano, Z.X. Sha, E. Peatman, J. Terhune, H. Li, H. Kucuktas, P. Li, E.S. Edholm, M. Wilson, Z.J. Liu. The two channel catfish intelectin genes exhibit highly differential patterns of tissue expression and regulation after infection with Edwardsiella ictaluri. Dev. Comp. Immunol. 32 (2008) 693-705.

[51] W. Thongda, C. Li, Y.P. Luo, B.H. Beck, E. Peatman. L-Rhamnose-binding lectins (RBLs) in channel catfish, Ictalurus punctatus: Characterization and expression profiling in mucosal tissues. Dev. Comp. Immunol. 44 (2014) 320-331.

[52] H. Zhang, E. Peatman, H. Liu, T.T. Feng, L.Q. Chen, Z.J. Liu. Molecular characterization of three L-type lectin genes from channel catfish, Ictalurus punctatus and their responses to Edwardsiella ictaluri challenge. Fish Shellfish Immunol. 32 (2012) 598-608.

[53] J. Yao, C. Li, J.R. Zhang, S.K. Liu, J.B. Feng, R.J. Wang, Y. Li, C. Jiang, L. Song, A.L. Chen, Z.J. Liu. Expression of nitric oxide synthase (NOS) genes in channel catfish is highly regulated and time dependent after bacterial challenges. Dev. Comp. Immunol. 45 (2014) 74-86.

[54] Y. Li, S. Liu, Z. Qin, J. Yao, C. Jiang, L. Song, R. Dunham, Z. Liu. The serpin superfamily in channel catfish: identification, phylogenetic analysis and expression profiling in mucosal tissues after bacterial infections. Dev. Comp. Immunol. 49 (2015) 267-277.

[55] J. Yao, W. Mu, S. Liu, J. Zhang, H. Wen, Z. Liu. Identification, phylogeny and expression analysis of suppressors of cytokine signaling in channel catfish. Mol. Immunol. 64 (2015) 276-284.

[56] Q. Fu, Y. Li, Y. Yang, C. Li, J. Yao, Q. Zeng, Z. Qin, S. Liu, D. Li, Z. Liu. Septin genes in channel catfish (Ictalurus punctatus) and their involvement in disease defense responses. Fish Shellfish Immunol. 49 (2016) 110-121.

[57] P. Baoprasertkul, C. He, E. Peatman, S. Zhang, P. Li, Z. Liu. Constitutive expression of three novel catfish CXC chemokines: homeostatic chemokines in teleost fish. Mol. Immunol. 42 (2005) 1355-1366.

[58] P. Baoprasertkul, E. Peatman, L. Chen, C. He, H. Kucuktas, P. Li, M. Simmons, Z. Liu. Sequence analysis and expression of a CXC chemokine in resistant and susceptible catfish after infection of Edwardsiella ictaluri. Dev. Comp. Immunol. 28 (2004) 769-780.

[59] L. Chen, C. He, P. Baoprasertkul, P. Xu, P. Li, J. Serapion, G. Waldbieser, W. Wolters, Z. Liu. Analysis of a catfish gene resembling interleukin-8: CDNA cloning, gene structure, and expression after infection with Edwardsiella ictaluri. Dev. Comp. Immunol. 29 (2005) 135-142.

[60] Z. Liu, S. Liu, J. Yao, L. Bao, J. Zhang, Y. Li, C. Jiang, L. Sun, R. Wang, Y. Zhang, T. Zhou, Q. Zeng, Q. Fu, S. Gao, N. Li, S. Koren, Y. Jiang, A. Zimin, P. Xu, A.M. Phillippy, X. Geng, L. Song, F. Sun, C. Li, X. Wang, A. Chen, Y. Jin, Z. Yuan, Y. Yang, S. Tan, E. Peatman, J. Lu, Z. Qin, R. Dunham, Z. Li, T. Sonstegard, J. Feng, R.G. Danzmann, S. Schroeder, B. Scheffler, M.V. Duke, L. Ballard, H. Kucuktas, L. Kaltenboeck, H. Liu, J. Armbruster, Y. Xie, M.L. Kirby, Y. Tian, M.E. Flanagan, W. Mu, G.C. Waldbieser. The channel catfish genome sequence provides insights into the evolution of scale formation in teleosts. Nat. Commun. 7 (2016) 11757.

[61] V. Solovyev, P. Kosarev, I. Seledsov, D. Vorobyev. Automatic annotation of eukaryotic genes, pseudogenes and promoters. Genome Biol. 7 Suppl 1 (2006) S10 11-12.

[62] R.C. Edgar. MUSCLE: a multiple sequence alignment method with reduced time and space complexity. BMC Bioinformatics 5 (2004) 113.

[63] K. Tamura, G. Stecher, D. Peterson, A. Filipski, S. Kumar. MEGA6: Molecular Evolutionary Genetics Analysis version 6.0. Mol. Biol. Evol. 30 (2013) 2725-2729.

[64] D. Darriba, G.L. Taboada, R. Doallo, D. Posada. ProtTest 3: fast selection of best-fit models of protein evolution. Bioinformatics 27 (2011) 1164-1165.

[65] A. Louis, M. Muffato, H. Roest Crollius. Genomicus: five genome browsers for comparative genomics in eukaryota. Nucleic Acids Res. 41 (2013) D700-705.

[66] C. Li, Y. Zhang, R. Wang, J. Lu, S. Nandi, S. Mohanty, J. Terhune, Z. Liu, E. Peatman. RNA-seq analysis of mucosal 
immune responses reveals signatures of intestinal barrier disruption and pathogen entry following Edwardsiella ictaluri infection in channel catfish, Ictalurus punctatus. Fish Shellfish Immunol. 32 (2012) 816-827.

[67] F. Sun, E. Peatman, C. Li, S. Liu, Y. Jiang, Z. Zhou, Z. Liu. Transcriptomic signatures of attachment, NF-kappaB suppression and IFN stimulation in the catfish gill following columnaris bacterial infection. Dev. Comp. Immunol. 38 (2012) 169-180.

[68] R. Wang, L. Sun, L. Bao, J. Zhang, Y. Jiang, J. Yao, L. Song, J. Feng, S. Liu, Z. Liu. Bulk segregant RNA-seq reveals expression and positional candidate genes and allele-specific expression for disease resistance against enteric septicemia of catfish. BMC Genomics 14 (2013) 929.

[69] E. Peatman, C. Li, B.C. Peterson, D.L. Straus, B.D. Farmer, B.H. Beck. Basal polarization of the mucosal compartment in Flavobacterium columnare susceptible and resistant channel catfish (Ictalurus punctatus). Mol. Immunol. 56 (2013) 317-327.

[70] B.H. Beck, B.D. Farmer, D.L. Straus, C. Li, E. Peatman. Putative roles for a rhamnose binding lectin in Flavobacterium columnare pathogenesis in channel catfish Ictalurus punctatus. Fish Shellfish Immunol. 33 (2012) 1008-1015.

[71] B.R. LaFrentz, C.A. Shoemaker, N.J. Booth, B.C. Peterson, D.D. Ourth. Spleen index and mannose-binding lectin levels in four channel catfish families exhibiting different susceptibilities to Flavobacterium columnare and Edwardsiella ictaluri. J. Aquat. Anim. Health 24 (2012) 141-147.

[72] J. Feng, Transcriptome and expression profiling of response to acute hypoxia in the gill of adult catfish, Plant and Animal Genome XXI Conference, Plant and Animal Genome, 2013.

[73] S. Hoegg, H. Brinkmann, J.S. Taylor, A. Meyer. Phylogenetic timing of the fish-specific genome duplication correlates with the diversification of teleost fish. J. Mol. Evol. 59 (2004) 190-203.

[74] F.G. Brunet, H. Roest Crollius, M. Paris, J.M. Aury, P. Gibert, O. Jaillon, V. Laudet, M. Robinson-Rechavi. Gene loss and evolutionary rates following whole-genome duplication in teleost fishes. Mol. Biol. Evol. 23 (2006) 18081816.

[75] A. Zlotnik, O. Yoshie. The chemokine superfamily revisited. Immunity 36 (2012) 705-716.

[76] D. Raman, T. Sobolik-Delmaire, A. Richmond. Chemokines in health and disease. Exp. Cell Res. 317 (2011) 575589.

[77] P.J. Hensbergen, P.G. Wijnands, M.W. Schreurs, R.J. Scheper, R. Willemze, C.P. Tensen. The CXCR3 targeting chemokine CXCL11 has potent antitumor activity in vivo involving attraction of CD8+ T lymphocytes but not inhibition of angiogenesis. J. Immunother. 28 (2005) 343-351.

[78] L. Sun, S. Liu, L. Bao, Y. Li, J. Feng, Z. Liu. Claudin multigene family in channel catfish and their expression profiles in response to bacterial infection and hypoxia as revealed by meta-analysis of RNA-Seq datasets. Comp. Biochem. Physiol. Part D Genomics Proteomics 13 (2015) 60-69. 


\section{Figure legends:}

Fig. 1. Phylogenetic analysis of $17 \mathrm{CXC}$ chemokine genes using amino acid sequences. The unrooted phylogenetic tree was conducted using maximum likelihood algorithm under the JTT + I + G model using MEGA6 software. The red clusters indicate fish CXC chemokine genes and black dots indicate catfish CXC chemokine genes. Bootstrap (1,000 replications) support values appear on the branches. Bootstrap values less than 50 are not shown. The Latin name and accession numbers were provided in Appendix: Supplementary File S2.

Fig. 2. Syntenic analysis of channel catfish CXC chemokine genes with zebrafish. (A) CXCL8; (B) CXCL11 and CXCL20; (C) CXCL12 and CXCL18. These syntenies were generated with the information obtained from the genome browser Genomicus. Full gene names were provided in Appendix: Supplementary File S2.

Fig. 3. Schematic genomic organization of catfish CXC chemokine subfamily genes. Arrowheads indicate CXC chemokine genes and their transcriptional orientation. The numbers under the chemokine genes indicated the numbers of coding exons.

Fig. 4. Expression of CXC chemokine genes in intestine after ESC infection at $3 \mathrm{~h}, 24 \mathrm{~h}$ and $72 \mathrm{~h}$. The $\mathrm{y}$ axis indicated fold change of CXC chemokine genes and the $\mathrm{x}$-Axis provided the names of the genes. Only the significantly expressed genes ( $\mid$ fold change $\mid \geq 2$, with the p-value $<0.05$ ) were presented.

Fig. 5. Expression of CXC chemokine genes in gill after F. columnare infection at $4 \mathrm{~h}, 24 \mathrm{~h}$ and $48 \mathrm{~h}$. The y-axis indicated fold change of CXC chemokine genes and the x-Axis provided the names of the genes. Only the significantly expressed genes ( $\mid$ fold change $\mid \geq 2$, with the $\mathrm{p}$-value $<0.05$ ) were presented.

Fig. 6. Comparison between resistant and susceptible catfish in liver after ESC infection. The y-axis 
indicated fold change of CXC chemokine genes and the x-Axis provided the names of the genes.Only the significantly expressed genes ( $\mid$ fold change $\mid \geq 2$, with the p-value $<0.05$ ) were presented.

Fig. 7. Comparison between resistant and susceptible catfish in gill after F. columnareinfection. The yaxis indicated fold change of CXC chemokine genes and the $\mathrm{x}$-Axis provided the names of the genes.Only the significantly expressed genes ( $\mid$ fold change $\mid \geq 2$, with the p-value $<0.05$ ) were presented.

Fig. 8. Comparison of CXC chemokine expression between tolerant and intolerant catfish in gill after hypoxia stress.The y-axis indicated fold change of CXC chemokine genes and the x-Axis provided the names of the genes.Only the significantly expressed genes ( $\mid$ fold change $\mid \geq 2$, with the p-value $<0.05$ ) were presented. 
1 Table 1. Identification of CXC chemokine genes in channel catfish genome.

2

\begin{tabular}{lccccccccccc}
\hline Chemokine & mRNA(bp) & CDS(bp) & domain & exons & Chr & Ori & location & Accession no. & Previous name & Reference \\
\hline CXCL8a & 506 & 91 & $24-85$ & 4 & 29 & + & $202466-203420$ & JT173315 & - & This study \\
CXCL8b.1 & 1165 & 90 & $26-86$ & 4 & 7 & + & $23242568-23244381$ & JT346615 & - & This study \\
CXCL8b.2 & 1283 & 109 & $42-105$ & 4 & 7 & + & $23253387-23257959$ & JT472937 & - & This study \\
CXCL11.1 & 627 & 102 & $27-89$ & 4 & 22 & - & $7715737-7716675$ & JT349732 & - & This study \\
CXCL11.2 & 722 & 126 & $57-119$ & 4 & 22 & - & $7724434-7725519$ & KX451318 & - & This study \\
CXCL11.3 & 666 & 95 & $26-88$ & 5 & 22 & - & $7732572-7736932$ & KX451319 & CXCL10 & {$[58]$} \\
CXCL12a & 590 & 99 & $29-87$ & 4 & 3 & + & $17602740-17609781$ & JT419405 & CXCL12 & [57] \\
CXCL12b & 874 & 99 & $29-87$ & 4 & 27 & + & $16062541-16067669$ & JT207644 & - & This study \\
CXCL13 & 885 & 101 & $31-92$ & 4 & 22 & - & $7693947-7696235$ & JT246782 & - & This study \\
CXCL14 & 1897 & 99 & $33-85$ & 4 & 8 & + & $15070664-15077125$ & JT320199 & CXCL14 & {$[57]$} \\
CXCL18a.1 & 1298 & 123 & $33-95$ & 4 & 3 & + & $17544506-17547785$ & JT246160 & - & This study \\
CXCL18a.2 & 748 & 125 & $31-91$ & 5 & 3 & + & $17531899-17533105$ & JT350998 & - & This study \\
CXCL18b & 816 & 131 & $29-84$ & 4 & 26 & + & $9685027-9686654$ & JT348632 & CXCL2-like & {$[57]$} \\
CXCL19 & 3040 & 99 & $28-89$ & 4 & 7 & + & $23263891-23268400$ & JT243812 & - & This study \\
CXCL20.1 & 778 & 90 & $27-86$ & 3 & 22 & - & $7707189-7708696$ & JT340266 & - & This study \\
CXCL20.2 & 866 & 108 & $29-91$ & 4 & 22 & - & $7719104-7720485$ & KX451320 & - & This study \\
CXCL20.3 & 991 & 111 & $29-92$ & 4 & 22 & - & $7728302-7729696$ & KX451321 & CXCL8 & {$[59]$} \\
\hline
\end{tabular}

3 
5 Table 2. Copy numbers of CXC chemokine genes in several representative vertebrate genomes.

6 Yellow shading indicated the mammal-specific CXC chemokine genes. Green shading indicated the 7 CXC chemokine genes harbored by all checked species. Blue shading indicated the lack of CXC

8 chemokine genes in tetrapod species. Bold numbers indicated the gene duplications.

9

\begin{tabular}{ccccccccccc}
\hline Genes & Catfish & Zebrafish & Medaka & Sole & Fugu & Frog & Chicken & Cow & Mouse & Human \\
\hline CXCL1 & 0 & 0 & 0 & 0 & 0 & 0 & 0 & 1 & 1 & 1 \\
CXCL2 & 0 & 0 & 1 & 0 & 0 & 1 & 0 & 1 & 1 & 1 \\
CXCL3 & 0 & 0 & 0 & 0 & 0 & 0 & 0 & 1 & 1 & 1 \\
CXCL4 & 0 & 0 & 0 & 0 & 0 & 0 & 0 & 0 & 1 & 1 \\
CXCL5 & 0 & 0 & 0 & 0 & 0 & 1 & 0 & 1 & 1 & 1 \\
CXCL6 & 0 & 0 & 1 & 1 & 0 & 0 & 0 & 0 & 0 & 1 \\
CXCL7 & 0 & 0 & 0 & 0 & 0 & 0 & 0 & 0 & 1 & 1 \\
CXCL8 & $\mathbf{3}$ & $\mathbf{4}$ & 0 & 0 & 0 & 1 & 1 & 1 & 0 & 1 \\
CXCL9 & 0 & 0 & 1 & 0 & 0 & 0 & 0 & 1 & 1 & 1 \\
CXCL10 & 0 & 0 & 0 & 1 & 0 & 1 & 0 & 1 & 1 & 1 \\
CXCL11 & $\mathbf{3}$ & $\mathbf{8}$ & 0 & 0 & 1 & 0 & 0 & 1 & 1 & 1 \\
CXCL12 & $\mathbf{2}$ & $\mathbf{2}$ & $\mathbf{2}$ & 1 & $\mathbf{2}$ & 1 & 1 & 1 & 1 & 1 \\
CXCL13 & 1 & 1 & 1 & 0 & 1 & 1 & 1 & 1 & 1 & 1 \\
CXCL14 & 1 & 1 & 1 & 1 & 1 & 1 & 1 & 1 & 1 & 1 \\
CXCL15 & 0 & 0 & 0 & 0 & 0 & 0 & 0 & 1 & 1 & 0 \\
CXCL16 & 0 & 0 & 0 & 0 & 0 & 0 & 0 & 1 & 1 & 1 \\
CXCL17 & 0 & 0 & 0 & 0 & 0 & 0 & 0 & 1 & 1 & 1 \\
CXCL18 & $\mathbf{3}$ & $\mathbf{3}$ & 0 & 0 & 0 & 0 & 0 & 0 & 0 & 0 \\
CXCL19 & 1 & 1 & 1 & 0 & 0 & 0 & 0 & 0 & 0 & 0 \\
CXCL20 & $\mathbf{3}$ & 1 & 0 & 0 & 0 & 0 & 0 & 0 & 0 & 0 \\
CXCL32 & 0 & $\mathbf{2}$ & 0 & 0 & 0 & 0 & 0 & 0 & 0 & 0 \\
\hline total & 17 & 23 & 8 & 4 & 5 & 7 & 4 & 14 & 15 & 16 \\
\hline & & & & & & & & & & 1 \\
\hline
\end{tabular}


Fig.1

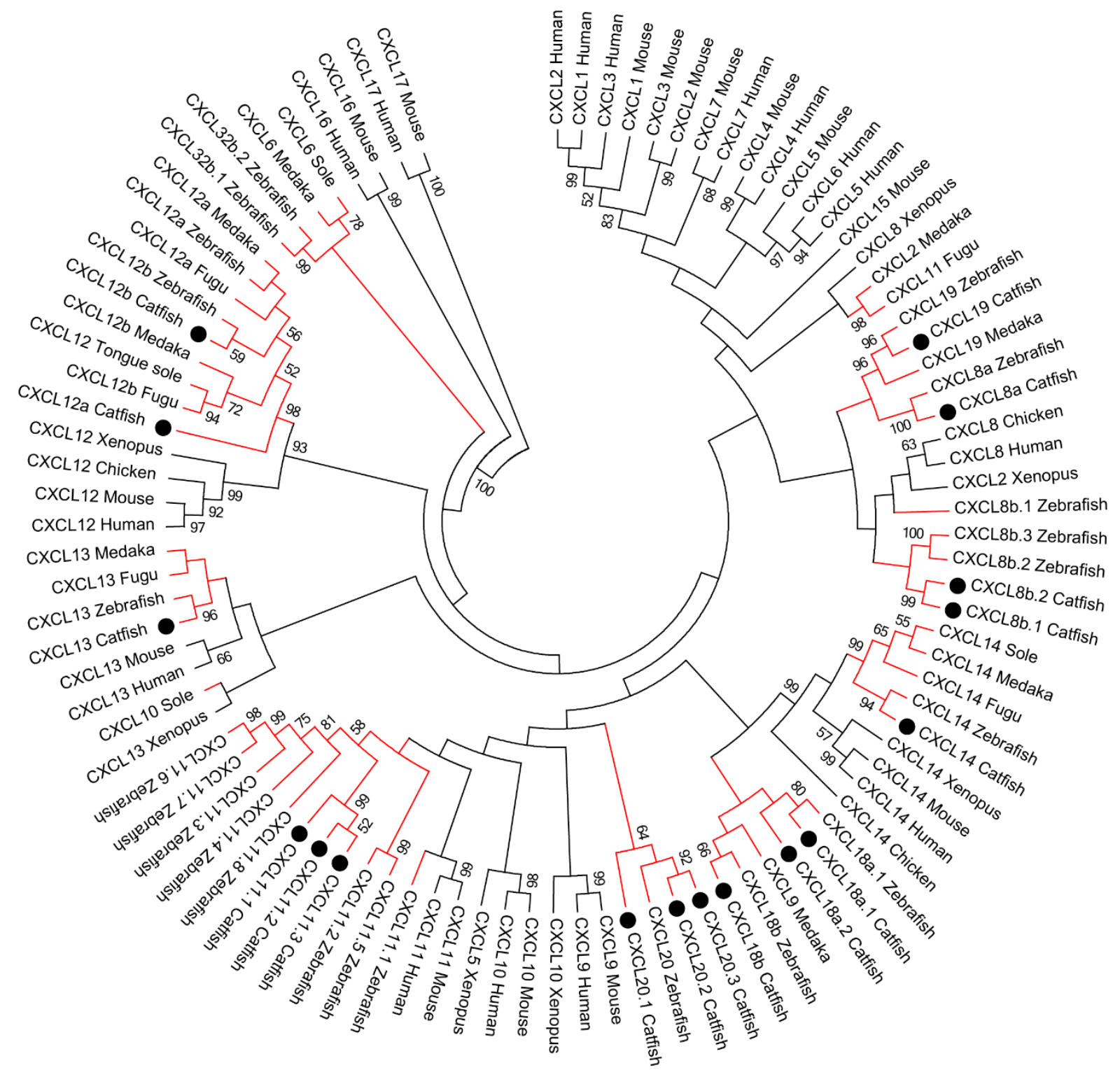


Fig. 2

A)

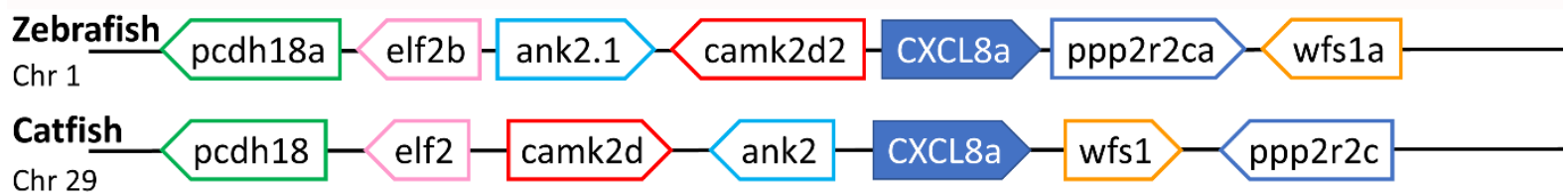

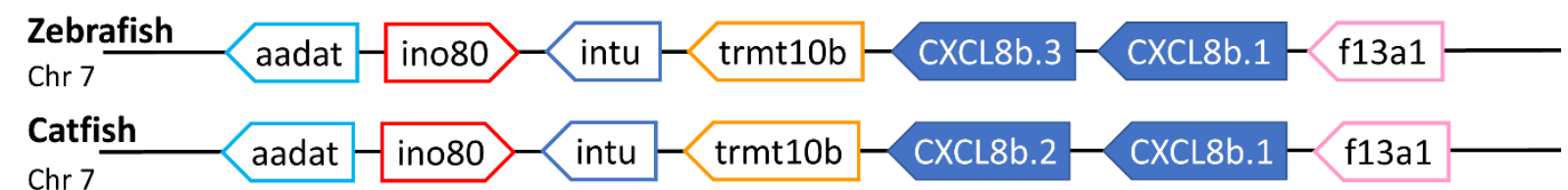

B)

Zebr 5 CXCL11.5 CXCL11.6 CXCL11.7-CXCL11.1 - CXCL20-rufy3 grsf1-mob1b-

Catfish CXCL20.1 CXCL11.1-CXCL20.2 CXCL11.2 CXCL20.3 CXCL11.3 rufy3 grsf1-mob1b -

C)
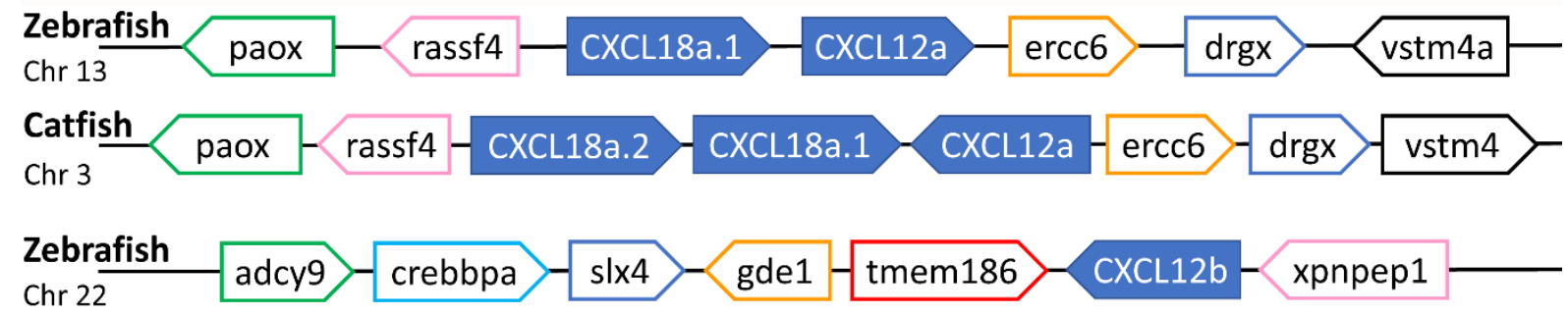

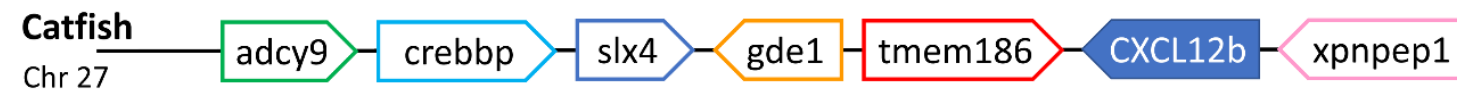

$\begin{aligned} & \text { Zebrafish } \\ & \text { Chr 1 }\end{aligned} \begin{aligned} & \text { sorcs3 } \\ & \text { (2 of 2) }\end{aligned}>$ CXCL18b $\begin{aligned} & \text { gsk3b } \\ & \text { (2 of 2) }\end{aligned}$ taf5 - pdcd11
Catfish
Chr 26


$20 \quad$ Fig. 3
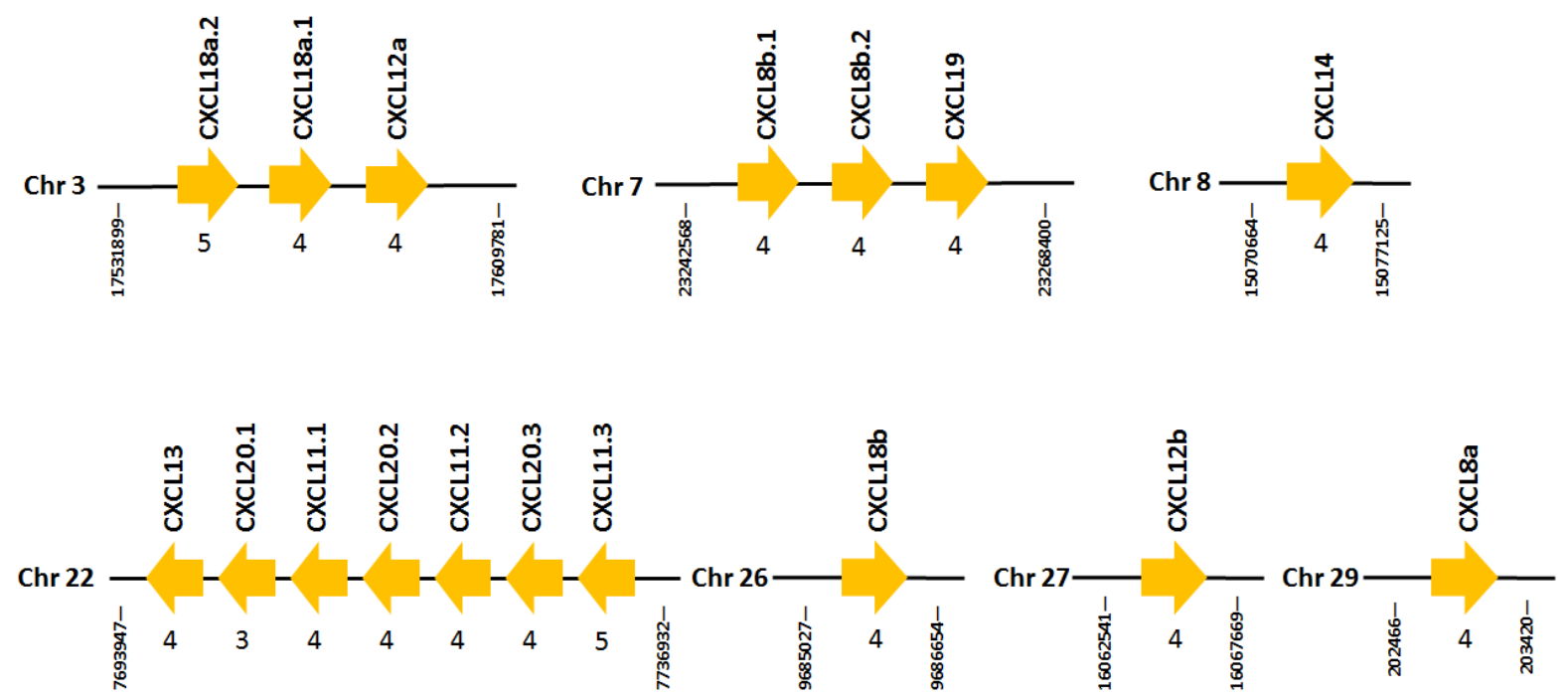
Fig.4

ESC_3 $\mathrm{h}$

ESC_24 h

ESC_72 h

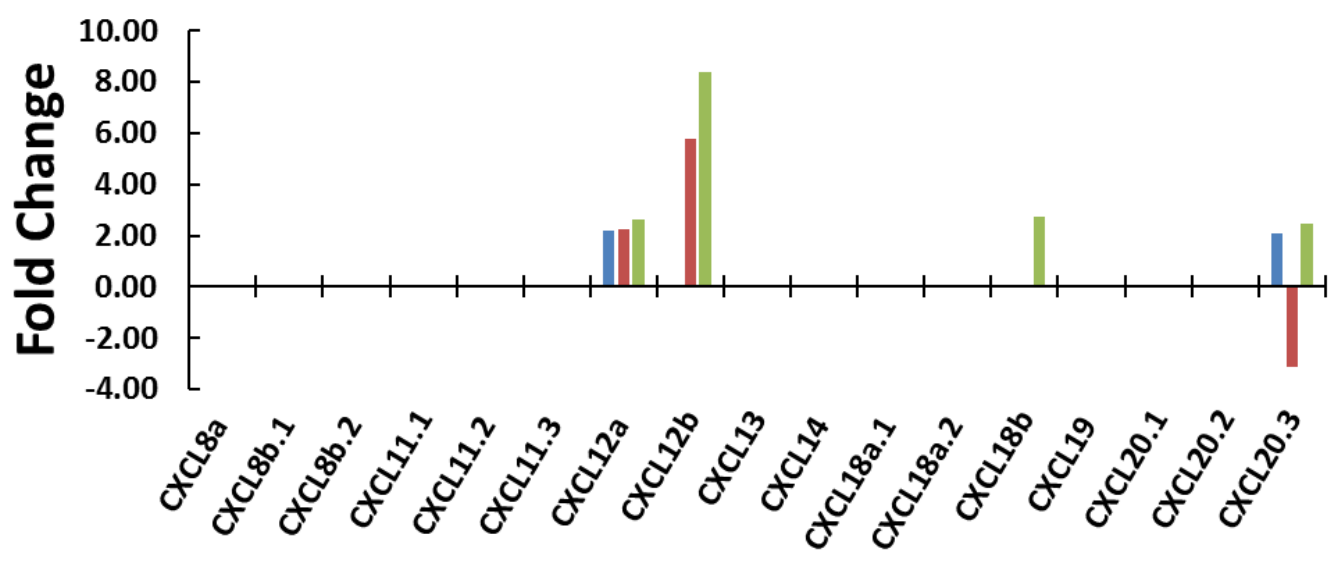

25 
Fig. 5
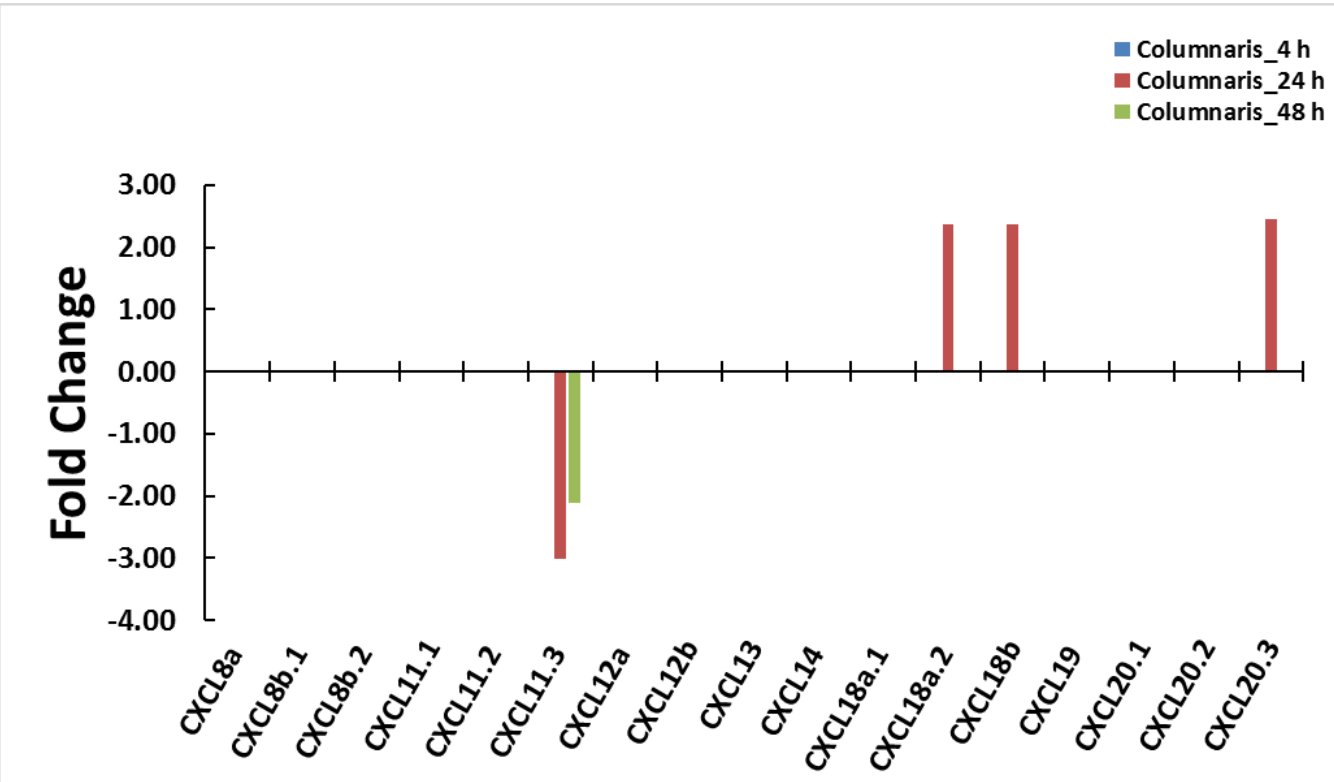
Fig. 6

31

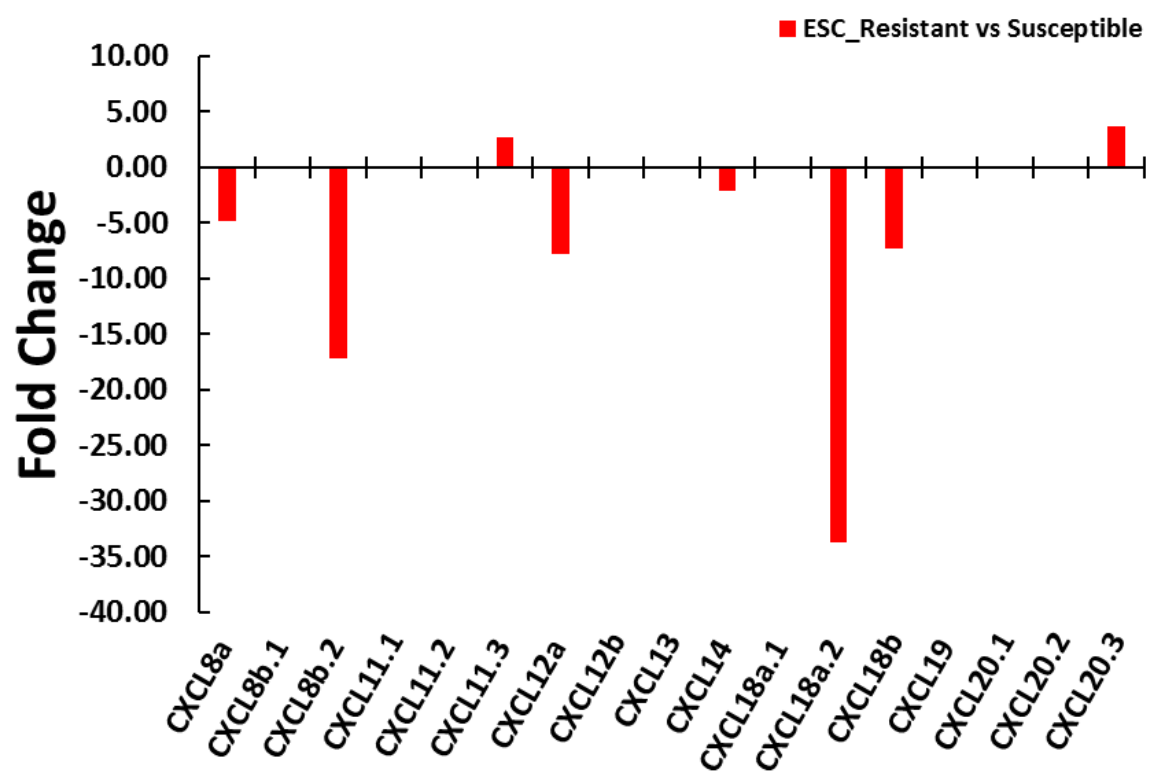

32 
Fig. 7

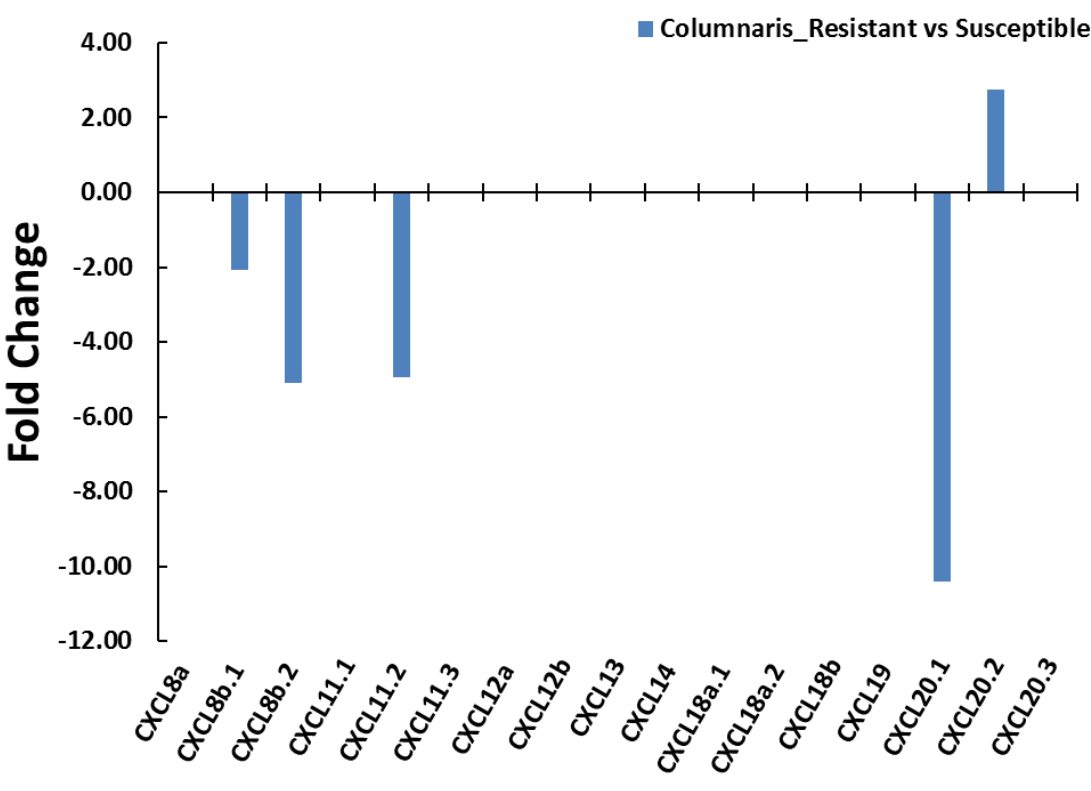


Fig. 8

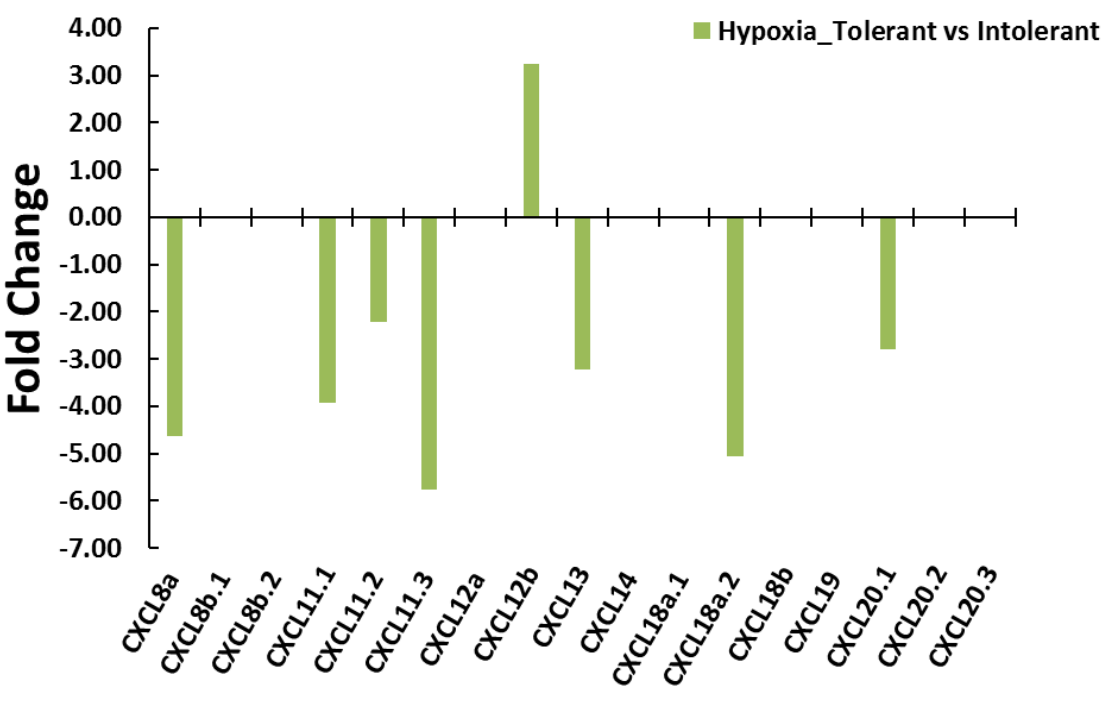

